\title{
Health care providers' knowledge, attitude and perceived stigma regarding tuberculosis in a pastoralist community in Ethiopia: a cross-sectional study
}

Bezawit Temesgen Sima ${ }^{1,3^{*}}$, Tefera Belachew ${ }^{2}$ and Fekadu Abebe ${ }^{3}$

\begin{abstract}
Background: Tuberculosis (TB) remains the prime killer disease among infectious diseases. TB control depends on early case detection and treatment in a directly observed treatment short course (DOTS) programme. The success of DOTS depends on the ability of the health care system to identify and properly manage TB cases. The present study aims to assess healthcare provider (HCP) knowledge, attitude and perceived stigma regarding TB and perception about traditional healers.

Methods: A descriptive cross sectional study was conducted among 108 HCPs using a semi-structured, selfadministered questionnaire from September 2014 to January 2015. The study district has a high TB burden area with one district hospital, 4 health centres, and 18 health posts. All health facilities and HCPs available during the study period in the district were included in the study. Statistical software for social science (SPSS) version 22 and STATA version 14 were used to enter and analyse data, respectively.

Results: The majority (64\%) of the HCPs had poor overall knowledge regarding TB, and 67.6 and $57.6 \%$ had poor knowledge regarding TB diagnosis and nature of the disease, respectively. Moreover, most 66.7 and $55.6 \%$ of the HCPs had an unfavourable attitude towards TB and TB control systems, respectively. Slightly under half (49.1\%) of the HCPs had a favourable attitude towards TB patients, and the majority (88.9\%) had low perceived stigma. The majority (87.0\%) of the HCPs indicated the importance of community involvement in TB control activity. Moreover, most (60.2\%) of the HCPs showed willingness to collaborate with traditional healers (THs) on TB control activity.

Conclusions: Healthcare workers' knowledge gap and unfavourable attitude towards TB control systems reported in this study may cause poor TB care delivery. HCPs' perception of the importance of community involvement in TB control and willingness to collaborate with THs on TB management could be an opportunity to strengthen the World Health Organization's (WHO's) component of End TB strategy through community engagement. Training and workshops could be used to address the knowledge gap and the unfavourable attitude regarding TB among HCPs.
\end{abstract}

Keywords: Attitude, Control, Health care workers, Kereyu, Knowledge, Pastoralists, Stigma tuberculosis

\footnotetext{
* Correspondence: b.t.sima@studmed.uio.no

'Department of Health Education and Behavioral Science, Institute of Health, Jimma University, P.O. Box 378, Jimma, Ethiopia

${ }^{3}$ Department of Community Medicine and Global Health, Institute for Health and Society, Faculty of Medicine, University of Oslo, P.O. Box 1130, Blindern, 0318 Oslo, Norway

Full list of author information is available at the end of the article
}

(c) The Author(s). 2019 Open Access This article is distributed under the terms of the Creative Commons Attribution 4.0 International License (http://creativecommons.org/licenses/by/4.0/), which permits unrestricted use, distribution, and reproduction in any medium, provided you give appropriate credit to the original author(s) and the source, provide a link to the Creative Commons license, and indicate if changes were made. The Creative Commons Public Domain Dedication waiver (http://creativecommons.org/publicdomain/zero/1.0/) applies to the data made available in this article, unless otherwise stated. 


\section{Background}

Tuberculosis (TB) is the leading cause of death and results in ill health for approximately 10 million people each year from a single infectious agent, ranking above human immunodeficiency virus/acquired immune deficiency syndrome (HIV/AIDS) [1]. Ethiopia ranks among the 30 highest TB burden countries, with estimated incidence of $200,000 \mathrm{~TB}$ per 100,000 populations in 2015 . It has fully integrated the World Health Organization (WHO) End TB strategy into the national TB prevention and care plan [2]. The WHO reported that more than 3 million people with TB are not accurately diagnosed by the health care system every year [3], and healthcare workers (HCWs) have been reported to play a major role contributing to the success of TB treatment and management [4].

In Ethiopia, TB treatment is provided free of charge at primary, secondary and tertiary levels of public health facilities. Primary health care is the main mode of health care delivery, and the first point of medical contact for most rural residents in the country and is delivered through health centres and health posts. The success of directly observed treatment short course (DOTS) depends on the ability of the health care system to identify and properly manage TB cases. This requires active involvement of the HCPs in TB diagnosis and management $[5,6]$. TB treatment should include counselling regarding disease progress and the importance of adherence to treatment. Failure to do so may result in the spread of TB and development of multi-drug resistant bacteria [7].

However, some studies reported misconceptions and lack of knowledge about TB among HCWs. For instance, a study in Iraq showed that only $12.6 \%$ of HCWs believe that TB is caused by bacteria, and another study in South Africa showed $21 \%$ of HCWs believe in prayer as treatment for TB $[8,9]$.

In pastoralist communities in Ethiopia, in addition to poor knowledge and poor healthcare-seeking behaviour [10-12], poor access to modern health care facility and quality of care has been a great challenge in the TB control activity [13-15]. Delays in the diagnosis and treatment of TB have also been reported [16-18]. Moreover, the Ethiopian national health care system has identified health extension workers (HEWs) as the first contact point in rural settings, which is difficult to implement in pastoralist communities due to their different lifestyle compared to non-pastoralists [19].

Studies have suggested that TB knowledge, attitude and stigma could be improved through training for HCWs and HCPs [20-22].

However, to our knowledge, there are no published reports on the knowledge, attitude and practice, and stigma towards TB among HCPs of pastoralist communities in
Ethiopia, where access to health care is limited [23] and cultural differences between HCPs and the community are reported to be a challenge in the primary health care delivery system [24]. Therefore, this study aims to assess HCPs' knowledge, attitude and perceived stigma regarding $\mathrm{TB}$ and perception regarding collaboration with traditional healers (THs) on TB control in the Kereyu pastoralist community in Ethiopia.

\section{Methods \\ Study area and population Study area}

This study was conducted in Fentalle (Kereyu pastoralist) Wereda (equivalent to district), located in the east Shoa zone of Oromia, in the southern part of the northern rift valley of Ethiopia. The area falls within an altitude range of 800-1100 masl. The total land area is $1170 \mathrm{~km}^{2}$ with a total population of 76,367 ; it is located $200 \mathrm{~km}$ east of the capital city, Addis Ababa. Metehara is the capital and administrative centre of the district. A detailed description of the study area is given elsewhere [10].

There are four health centres and 18 health posts for the entire population of the Kereyu District. There is one referral hospital in Metehara Sugar Corporation called Merti Hospital. There was a total of 65 HEWs and 46 other health professionals (clinical nurses, midwifes, environmental health workers and pharmacy technicians and laboratory technicians) in the district, excluding the HCPs working at Merti Hospital, which is not the administrative unit of the district health office but does provide services to the pastoralist community. The number of HEWs reported at the district health office includes those training for upskilling, travelling for workshops, not available due to maternity or sick leave as well as those in the process of transfer to other districts. We included all available HEWs at the health posts during the study period.

\section{Study design and sampling}

We conducted a facility-based cross sectional study from September 2014 to January 2015.

Before the actual data collection, we identified all the health facilities in the district with the help of HEWs and identified the TB focal person responsible for coordinating the district's TB prevention and care activities. We included all HCPs and HEWs in the district in the study. Those who were available during the study period were given a self-administered questionnaire to complete and return. If the HCPs reported insufficient time to return the questionnaire the same day, they were allowed to return it the next day. 


\section{Measurements}

Data were collected using semi-structured and self-administered questionnaires prepared in English as in previous similar studies $[20,21,25]$ and translated to Amharic (the federal working language). We gave training to three experienced local coordinators and involved them in the facilitation of the data collection process with the principal investigator.

The survey contained 71 questions, with sections on sociodemographic characteristics, TB knowledge, attitude, perceived stigma regarding $\mathrm{TB}$ and perception of collaboration with traditional healers. The tools were pre-tested before the actual data collection to assess the comprehensibility of the questionnaire.

\section{Knowledge}

Knowledge is defined as the fact or condition of knowing something with familiarity gained through experience or association [22]. The knowledge section had 24 questions and was divided into three sections: TB diagnosis (10 questions about signs and symptoms of susceptive $\mathrm{TB}$, active $\mathrm{TB}$ and relapse $\mathrm{TB}$ ), nature of the disease (12 questions about transmission, cause, factors in the spread of TB) and treatment duration (2 questions, one for intensive phase and one for the whole duration of $\mathrm{TB}$ treatment required). The correct (yes) response to each question was scored as one for a positive response, and incorrect (no/I don't know) response was scored as zero for a negative response. The scores were added together to generate a knowledge score from 0 to 24 (including each sign and symptom mentioned and factors for the exposure of TB), and the overall score was dichotomized using a median of 18 as a cut-off value. Those who scored 18 and above were coded " 1 " for good overall TB knowledge, and those below 18 coded "0" for poor overall TB knowledge. Likewise, scores were generated for the two sub-scales of knowledge regarding TB (TB diagnosis and nature of the disease), and the sub-scale of knowledge was categorized as poor and good levels of knowledge.

The term 'nature of the disease' is used to summarize the response of the HCPs about the organ affected most by $\mathrm{TB}$, transmission, cause, factors for the spread of $\mathrm{TB}$ and the public importance of TB in the community.

\section{Attitude}

Attitude is defined as how people feel about certain subjects or issues [21]. The attitude section contained 10 questions addressing two sub sections: attitude towards TB patients (3 questions) and attitude towards TB control (7 questions). A 5-point Likert scale was used to obtain responses to these questions and was treated as a continuous interval variable for analysis. The overall score for attitude regarding TB, attitude towards TB patients and TB control system was obtained by computing the included items using the SPSS syntax Compute by summing included items and multiplying the sum by 5 (number of Likert points). The attitude score was not normally distributed, therefore, overall attitude score was dichotomized using the median score of 37 as a cut-off value; those who had a mean score of 37 and above were coded " 1 " for a favourable attitude regarding TB and below 37 coded " 0 ", indicating an unfavourable attitude regarding TB.

\section{Perceived stigma}

Perceived stigma refers to the fear of discrimination or, in general, to the awareness of negative attitude and/or practices related to a particular condition [26]. The perceived stigma section had three sections: feeling about a person with $\mathrm{TB}$, perceived community feelings towards TB patients and feelings about being near a person with TB. The first section had five items and was summed to

Table 1 Socio-demographic characteristics of HCPs in the Kereyu pastoralist district, Ethiopia

\begin{tabular}{|c|c|c|}
\hline Variables & Frequency $(n=108)$ & Percent $\%$ \\
\hline \multicolumn{3}{|l|}{$\overline{\text { Age }}$} \\
\hline$<30$ & 68 & 63.0 \\
\hline $30-40$ & 26 & 24.1 \\
\hline$>40$ & 14 & 13.0 \\
\hline \multicolumn{3}{|l|}{ Sex } \\
\hline Male & 63 & 58.3 \\
\hline Female & 45 & 41.7 \\
\hline \multicolumn{3}{|l|}{ Profession } \\
\hline Medical doctor & 3 & 2.8 \\
\hline BSc Nurses & 53 & 49.1 \\
\hline Health officers & 27 & 25.0 \\
\hline Pharmacists & 1 & 0.9 \\
\hline HEWs & 24 & 22.2 \\
\hline \multicolumn{3}{|l|}{ Work duration } \\
\hline$<2$ years & 35 & 32.4 \\
\hline $3-5$ years & 27 & 25.0 \\
\hline 6 to 10 years & 28 & 25.9 \\
\hline$>10$ years & 18 & 16.7 \\
\hline \multicolumn{3}{|c|}{ Work at the DOTS unit } \\
\hline$<6$ months & 15 & 13.9 \\
\hline$>6$ months & 70 & 64.8 \\
\hline Never & 23 & 21.3 \\
\hline \multicolumn{3}{|c|}{ Attended DOTS/TB training } \\
\hline Yes & 40 & 37.0 \\
\hline No & 68 & 63.0 \\
\hline \multicolumn{3}{|c|}{ Provide health education on TB } \\
\hline Yes & 55 & 50.9 \\
\hline
\end{tabular}


create a perceived stigma score towards TB patients for analysis. Each item was coded as a "yes" or "no" response where 'yes' indicated the absence of perceived stigma and 'no' indicated the presence of perceived stigma. Negatively stated questions were reverse coded to obtain the correct scoring. The responses consistent with "lack of stigma" were scored one and the rest scored zero. The sum of the responses to (1) I feel compassion and desire to help; (2) I feel compassion but tend to stay away from TB patients; (3) It is their problem, and I cannot get TB; (4) I feel fear because they might infect me; and (5) I have no particular feelings were used to generate stigma score from 0 to 5 . The overall score was dichotomized using the median as a cut-off point. Since the stigma scores were not normally distributed, the median score (median $1, I Q R=1$ ) was used to classify the HCPs as having high or low perceived stigma towards TB patients. Those who have a score above 1 were coded as one, showing high perceived stigma towards TB patients, and those who scored 1 or lower were coded as zero, showing low perceived stigma towards TB patients (Additional file 1).

\section{Perception about THs}

Perception is man's primary form of cognitive contact with the world around him [27]. In this study, we assessed the HCPs' perception for possible future collaboration of the conventional health system with THs on TB control. Perception of the HCPs regarding collaboration with THs and their willingness to collaborate on TB prevention and care was assessed using 17 items. The questions had multiple choice and 'yes' or 'no' responses. The proportion of responses to some of the items used and relationship to the conclusion of this paper is reported.

\section{Data analysis}

\section{Quantitative data}

The data were entered and analysed using statistical software for social science (SPSS) version 22 and STATA version 14. We applied descriptive statistics to summarize the socio-demographic status of the HCPs, describe their knowledge and attitude and perceived stigma regarding TB and their perception about collaboration with THs on TB diagnosis and treatment. A Chi-square test was used in bivariate analysis to determine the association between the outcome variables and selected covariates. Univariate logistic regression was used to assess the strength of the association. The statistical significance of the differences was evaluated using $p$ value $<0.05$ and a $95 \%$ confidence interval.

Table 2 Knowledge level and factors associated with knowledge regarding TB among HCPs in Kereyu pastoralist district, Ethiopia

\begin{tabular}{|c|c|c|c|c|}
\hline Variable & Median (Q1,Q3) & \multicolumn{3}{|c|}{ Knowledge Level } \\
\hline \multicolumn{2}{|l|}{ Knowledge category } & $\begin{array}{l}\text { poor } \\
\text { NO. (\%) }\end{array}$ & \multicolumn{2}{|l|}{$\begin{array}{l}\text { good } \\
\text { NO. (\%) }\end{array}$} \\
\hline Towards nature of the disease & $6(6,7)$ & $62(57.64)$ & \multicolumn{2}{|l|}{$46(42.6)$} \\
\hline Towards TB diagnosis & $10(6,11)$ & $73(67.6)$ & \multicolumn{2}{|l|}{$35(32.4)$} \\
\hline \multirow[t]{2}{*}{ Overall TB knowledge } & $18(14,19)$ & $69(63.9)$ & $39(31.6)$ & \\
\hline & & \multicolumn{3}{|c|}{ Knowledge about TB diagnosis } \\
\hline Attending TB training & COR & Poor NO. (\%) & Good NO. (\%) & $P$ \\
\hline Yes & 2.45 & $22(30.0)$ & $18(51.4)$ & 0.03 \\
\hline \multirow[t]{2}{*}{ No } & Ref. & $51(69.9)$ & $17(48.6)$ & - \\
\hline & & \multicolumn{3}{|c|}{ Knowledge about the nature of TB } \\
\hline Duration of work at DOTS unit & COR & Poor NO. (\%) & Good NO. (\%) & \\
\hline$<6$ months & 5.39 & $6(9.7)$ & $9(19.6)$ & 0.02 \\
\hline$>6$ months & 3.05 & $38(61.3)$ & $32(69.6)$ & 0.047 \\
\hline \multirow[t]{2}{*}{ Never } & Ref. & $18(29.0)$ & $5(10.9)$ & - \\
\hline & & \multicolumn{3}{|c|}{ Overall Knowledge regarding TB } \\
\hline Duration of work at the health facility & COR & Poor NO. (\%) & Good NO. (\%) & \\
\hline$<2$ years & 4.3 & $20(29.0)$ & $15(38.5)$ & 0.02 \\
\hline $3-5$ years & Ref. & $23(33.3)$ & $4(10.3)$ & - \\
\hline $6-10$ years & 4.3 & $16(23.2)$ & $12(30.8)$ & 0.03 \\
\hline$>10$ years & 4.6 & $10(14.5)$ & $8(20.5)$ & 0.03 \\
\hline
\end{tabular}

*COR - crude odds ratio

${ }^{*} \mathrm{Q} 1$ and $\mathrm{Q} 3$ - quartile 1 and 3 
Table 3 HCPs' Knowledge regarding TB in Kereyu pastoralist district, Ethiopia

\begin{tabular}{|c|c|c|c|c|}
\hline Variables & Frequency $(n=108)$ & \multicolumn{3}{|l|}{ Percent (\%) } \\
\hline \multicolumn{5}{|l|}{ Cause of TB } \\
\hline Mycobacterium tuberculosis & 106 & \multicolumn{3}{|l|}{98.1} \\
\hline Mycobacterium pneumonia & 1 & \multicolumn{3}{|l|}{0.9} \\
\hline Mycobacterium contagiosum & 1 & \multicolumn{3}{|l|}{0.9} \\
\hline \multicolumn{5}{|l|}{ Organs most affected } \\
\hline Lung & 97 & \multicolumn{3}{|l|}{89.8} \\
\hline Bones & 8 & \multicolumn{3}{|l|}{7.4} \\
\hline Kidney & 2 & \multicolumn{3}{|l|}{1.9} \\
\hline Abdominal organs & 1 & \multicolumn{3}{|l|}{0.9} \\
\hline \multicolumn{5}{|l|}{ Routes of TB transmission } \\
\hline Droplets from coughing and sneezing of a person with active TB & 94 & \multicolumn{3}{|l|}{87} \\
\hline Sharing cups & 13 & \multicolumn{3}{|l|}{12} \\
\hline Handshaking & 1 & \multicolumn{3}{|l|}{0.9} \\
\hline \multicolumn{5}{|l|}{ Factors for the spread of TB } \\
\hline Household contact & 98 & \multicolumn{3}{|l|}{90.7} \\
\hline Overcrowding & 6 & \multicolumn{3}{|l|}{5.6} \\
\hline Humidity & 10 & \multicolumn{3}{|l|}{9.3} \\
\hline Poor nutrition & 6 & \multicolumn{3}{|l|}{5.6} \\
\hline People at high risk of developing TB & Yes & Percent\% & No & Percent \% \\
\hline HIV positive & 94 & 87 & 14 & 13 \\
\hline People in contact with TB patient & 46 & 42.6 & 62 & 57.4 \\
\hline People with chronic disease & 28 & 25.9 & 80 & 74.1 \\
\hline Pregnant women & 6 & 5.6 & 102 & 94.4 \\
\hline \multicolumn{5}{|l|}{ Infectious type of TB } \\
\hline Active pulmonary TB & 100 & \multicolumn{2}{|l|}{92.6} & 7.4 \\
\hline TB in other organs/body parts & 8 & \multicolumn{2}{|l|}{7.4} & 1.9 \\
\hline \multicolumn{5}{|l|}{ Symptoms suspicious for TB } \\
\hline Cough for more than three weeks & 74 & 68.5 & 34 & 31.5 \\
\hline Fever & 87 & 80.6 & 21 & 19.4 \\
\hline Haemoptysis & 94 & 87 & 14 & 13 \\
\hline Night sweating & 83 & 76.9 & 25 & 23.1 \\
\hline Loss of appetite & 78 & 72.2 & 30 & 27.8 \\
\hline Loss of weight & 77 & 71.3 & 31 & 28.7 \\
\hline General weakness & 71 & 65.7 & 337 & 34.3 \\
\hline Chest pain & 82 & 75.9 & 26 & 24.1 \\
\hline \multicolumn{5}{|l|}{ Diagnosis of Active PTB } \\
\hline Two or three positive smear tests & 95 & 88.0 & & \\
\hline One positive smear and positive $X$-ray & 13 & 12.0 & & \\
\hline Relapse TB & & & & \\
\hline Completed treatment. Cured and returned with positive smear & 84 & 77.8 & & \\
\hline Under treatment \& sputum remains positive after 5 months & 10 & 9.3 & & \\
\hline Interrupted treatment for 3 months and returned with positive smear & 14 & 13 & & \\
\hline Duration of active PTB treatment & & & & \\
\hline 6 months & 102 & 94.4 & & \\
\hline
\end{tabular}


Table 3 HCPs' Knowledge regarding TB in Kereyu pastoralist district, Ethiopia (Continued)

\begin{tabular}{lll}
\hline Variables & Frequency $(n=108)$ & Percent (\%) \\
\hline 9 months & 3 & 2.8 \\
$2-5$ months & 1 & 0.9 \\
Do not know & 1 & 0.9 \\
Duration of intensive TB treatment phase & 94 & 87.0 \\
2 months & 11 & 10.2 \\
6 months & 1 & 0.9 \\
9 months & 2 & 1.9 \\
12 months & & 29.6 \\
MDR-TB & 32 & 45.4 \\
When the bacilli is resistant to all currently available drugs of TB & 49 & 21.3 \\
When the bacilli is resistant to at least isoniazid and pyrazinamide & 23 & 3.7 \\
When the bacilli is very aggressive and you need at least 8 to 12 months of treatment & 4 & 23 \\
Others & &
\end{tabular}

*MDR-TB - Multi-drug resistant TB

\section{Results}

In total, 108 HCPs participated in the study. Fifty-eight percent were male with most (63\%) less than 30 years old (mean age 29). A large proportion of the study participants were nurses followed by health officers, accounting for 49.1 and $25.0 \%$, respectively, while $22 \%$ were HEWs. Sixty-three percent of the HCPs do not have TB-related training, while $65 \%$ of the respondents had worked in the TB unit for more than 6 months (Table 1).

\section{Knowledge regarding TB}

Table 2 shows the overall knowledge of the HCPs regarding $\mathrm{TB}$ and factors associated with this knowledge. Approximately $64 \%$ of HCPs had a poor level of knowledge about TB. Most of the HCWs also had poor knowledge of the nature of the disease (57.6\%) and aspects of TB diagnosis (67.6\%). HCWs who had worked for $<2$ years, $6-10$ years and $>10$ years had better overall knowledge regarding $\mathrm{TB}$ by 4.3 and 4.6 points, respectively compared with HCWs with working duration of $3-5$ years $(p=0.02, p=0.03$ and $p=0.03$, respectively).

Attending TB training was associated with a 2.45-point increase in knowledge score about TB diagnosis compared with those who had never attended TB training $(p=0.03)$. Working at the DOTS units increased knowledge about the nature of TB (for less than 6 months yielded a 5.39-point increase and greater than 6 months with a 3.05-point increase, respectively) compared with those who had never worked at the DOTS unit $(p=0.02$ and $p=0.047$, respectively) (Table 2).

Regarding HCPs' knowledge of the body organs most affected by TB (Table 3), the majority (89.7\%) answered that $\mathrm{TB}$ affects the lungs, while $7.4,1.9$ and $0.9 \%$ reported that it affects the bones, kidney and abdominal

Table 4 Attitude Score towards TB and factors associated with overall attitude towards TB

\begin{tabular}{llll}
\hline Variable & Median score (Q1, Q3) & Attitude & \\
& & $\begin{array}{l}\text { Favourable } \\
\text { NO. (\%) }\end{array}$ & \\
& & $48(44.4)$ & \\
Towards TB control & $26(23,30)$ & $36(33.3)$ & $72(66.7)$ \\
Towards TB patient & $12(10,13)$ & $53(49.1)$ & $55(50.9)$ \\
Overall Attitude & $37(34,42)$ & & \\
Overall Attitude towards TB & & People with HIV are most affected by TB \\
& COR & Yes No & \\
& & No. \% No. \% & \\
Favourable & $50(53.2)$ & $3(21.4) *$ \\
Unfavourable & 4.1 & $44(46.8)$ & $11(78.6)$ \\
\hline
\end{tabular}

COR - crude odds ratio

Q1 and Q3 - quartile 1 and 3

*Reference 
Table 5 HCPs' attitude towards TB in Kereyu pastoralist district in Ethiopia

\begin{tabular}{|c|c|c|c|c|c|}
\hline & Strongly agree & Agree & Neutral & Disagree & Strongly disagree \\
\hline New cases of TB are major challenges for TB control & $38(35.2 \%)$ & $33(30.6 \%)$ & $13(12.0 \%)$ & $15(13.9 \%)$ & $9(8.3 \%)$ \\
\hline Community involvement is important in TB prevention and control & $94(87.0 \%)$ & $13(12.0 \%)$ & $1(0.9)$ & 0 & 0 \\
\hline $\begin{array}{l}\text { TB patients do not understand why they should take the medication } \\
\text { after starting to feel better }\end{array}$ & $36(33.3 \%)$ & $51(47.2)$ & $9(8.3 \%)$ & $10(9.3 \%)$ & $2(1.9 \%)$ \\
\hline MDR-TB is a major public health problem in your community & $58(53.7 \%)$ & $29(26.9 \%)$ & $5(4.6 \%)$ & $14(13.0 \%)$ & $2(1.9 \%)$ \\
\hline Using DOTS makes a difference in treatment compliance & $25(23.1 \%)$ & $34(31.5 \%)$ & $22(20.4 \%)$ & $22(20.4 \%)$ & $5(4.6 \%)$ \\
\hline A person with TB faces stigma and shame in your community & $27(25.0 \%)$ & $26(24.1 \%)$ & $18(16.7 \%)$ & $33(30.6 \%)$ & $4(3.7 \%)$ \\
\hline $\begin{array}{l}\text { DOTS implementation should take individual circumstances } \\
\text { in to consideration }\end{array}$ & $32(29.6 \%)$ & $23(21.3 \%)$ & $9(8.3 \%)$ & $32(29.6 \%)$ & $12(11.1 \%)$ \\
\hline Poor knowledge about TB makes it difficult to follow DOTS & $36(33.3 \%)$ & $52(48.1 \%)$ & 0 & $15(13.9 \%)$ & $5(4.6 \%)$ \\
\hline TB treatment we provide is accepted by the clients & $48(44.4 \%)$ & $40(37.0 \%)$ & $12(11.1 \%)$ & $3(2.8 \%)$ & $5(4.6 \%)$ \\
\hline Most HCWs at this facility have adequate training for TB control activities & $17(15.7 \%)$ & $23(21.3 \%)$ & $9(8.3 \%)$ & $44(40.7 \%)$ & $15(13.9 \%)$ \\
\hline
\end{tabular}

organs, respectively. Moreover, $90.7 \%$ of the HCPs mentioned that the main risk factor for the spread of TB infection is close household contact with an active TB patient, while 5.6, 9.3 and $5.6 \%$ said that overcrowding, humidity and poor nutrition, respectively, was the risk factor for the spread of TB. In addition, $77.8 \%$ of the HCPs knew the correct definition of relapse TB (patient cured/completed treatment and return with smear positive sputum). Concerning the duration of TB treatment for new diagnosed active anti-pulmonary TB, 94.4\% answered correctly (6 months) (Table 3$)$.

\section{Attitude towards TB}

Table 4 shows that $53.7 \%$ of the HCPs had an unfavourable attitude towards TB. A large proportion (55.6\%) had an unfavourable attitude towards TB control systems. A large proportion (66.7\%) of the HCPs had an unfavourable attitude towards TB patients. Those who believed that people with HIV are most affected by TB had approximately a 4 times more favourable attitude towards TB compared with those who did not mention people with HIV as a high risk group for TB $(p=0.027)$.

Eighty-seven percent of the respondents strongly agreed with the statement that community engagement is essential for TB control, and a substantial proportion
(44.4\%) of the HCPs also strongly agreed that the service they provide is accepted in the community (Table 5).

\section{Perceived stigma towards TB patients}

Regarding the perceived stigma of HCPs towards TB patients, the majority $(88.9 \%)$ had low perceived stigma and few $(11.1 \%)$ had high perceived stigma towards TB patients. Table 6 shows that overall knowledge of the HCPs towards TB is significantly associated with the perceived stigma of the HCPs towards TB patients $(p<0.001)$.

The majority of the HCPs (75.9\%) mentioned feeling compassion and a desire to help; $56.5 \%$ indicated that the community mostly supports TB patients (Table 7 ).

\section{Perception of HCPs towards collaboration with THs}

Table 8 shows that the majority $(60.2 \%)$ of HCPs are willing to work in collaboration with THs. Referral of potential TB patients by THs $(29.8 \%)$ and cross visiting (29.9\%) were among the possible methods of collaboration on TB prevention and care mentioned by HCPs.

\section{Discussion}

The current study assessed the knowledge, attitude and perceived stigma of HCPs regarding TB and perception of THs. The results show that the majority of the HCPs had poor overall knowledge regarding $\mathrm{TB}$, with particularly

Table 6 Factors associated with perceived stigma towards TB patients in Kereyu pastoralist district, Ethiopia

\begin{tabular}{|c|c|c|c|}
\hline \multirow{2}{*}{$\begin{array}{l}\text { Variables } \\
\text { Overall knowledge towards TB }\end{array}$} & \multicolumn{2}{|l|}{ Perceived stigma level } & \multirow[b]{2}{*}{$P$ value } \\
\hline & $\begin{array}{l}\text { Low perceived stigma } \\
\text { No. (\%) }\end{array}$ & $\begin{array}{l}\text { High perceived stigma } \\
\text { No. }(\%)\end{array}$ & \\
\hline Good knowledge & 39 (40.6) & $0(00.0)$ & 0.001 \\
\hline Poor knowledge & $\begin{array}{l}57 \\
(59.4)\end{array}$ & $12(100.0)$ & \\
\hline
\end{tabular}


Table 7 HCPs' Perceived stigma towards TB in Kereyu pastoralist district, Ethiopia

\begin{tabular}{|c|c|c|}
\hline Variables & Frequency $(n=108)$ & Percent $\%$ \\
\hline \multicolumn{3}{|l|}{ Feeling about a person with TB } \\
\hline I feel compassion and a desire to help & 82 & 75.9 \\
\hline I feel compassion but I tend to stay away from these people & 8 & 7.4 \\
\hline I am afraid of them because they might infect me & 4 & 3.7 \\
\hline I have no particular feeling & 14 & 13.0 \\
\hline \multicolumn{3}{|l|}{ TB is a shameful disease } \\
\hline Yes & 33 & 30.6 \\
\hline No & 75 & 69.4 \\
\hline \multicolumn{3}{|l|}{ How TB patients are regarded/treated in the community } \\
\hline Most people reject him or her & 23 & 21.3 \\
\hline Most people are friendly but they generally avoid him/her & 32 & 21.3 \\
\hline The community mostly supports her/him & 61 & 56.5 \\
\hline Others & 1 & 0.9 \\
\hline \multicolumn{3}{|l|}{ Feeling around a person having TB } \\
\hline I feel like I would get infected so I will make my conversation short & 25 & 23.1 \\
\hline I feel like I have to keep my distance & 9 & 8.3 \\
\hline I feel like I have to be supportive & 73 & 67.6 \\
\hline Others (no particular feeling) & 1 & 0.9 \\
\hline
\end{tabular}

poor knowledge about the nature of the disease and aspects of diagnosis. In addition, most of the HCPs had an unfavourable attitude towards TB and TB patients as well as the TB control system. Interestingly, most HCPs in this study had low perceived stigma towards TB patients.

The low level of knowledge regarding TB among HCPs in this study is in line with other studies examining communities with similar high TB burden and rural settings in African countries [28, 29] and other settings [30]. These results also indicated that attending $\mathrm{TB}$ training increased HCPs' knowledge regarding TB diagnosis more than two-fold compared with those who did not have TB training. In addition, a longer duration of work and working for less than 2 years at the healthcare facility and experience working at the DOTS unit are significantly associated with increased knowledge regarding TB. This might indicate a lack of training and updating the HCPs with new and current national TB control guidelines in the district. HCPs' knowledge regarding diagnosis and management of TB is crucial for TB control through proper case management, and it has a direct impact on the effectiveness and quality of the health care provided [7, 31, 32].

The majority of the HCPs in this study knew that bacteria cause TB. This is in contrast to studies in Iraq and South Africa, where misconceptions about $\mathrm{TB}$ among health care workers were more frequent. For instance, a study in Iraq [20] showed that only $12.6 \%$ of HCWs believed TB is caused by bacteria, and another study in south Africa showed 21\% of HCWs believe in prayer as a treatment for TB [8].
In the present study, most HCPs had an unfavourable attitude towards TB, and most also demonstrated an unfavourable attitude towards TB patents and TB control system. Studies reported that the negative attitude of providers towards TB patients and the existing treatment system has led to a high treatment dropout rate, while home visits by providers and supportive and caring staff resulted in high treatment compliance and positive experience with DOTS $[4,30]$.

In the present study, the majority of the HCPs acknowledged the importance of community involvement in TB control activities and expressed their willingness to collaborate with THs on TB control activities. In this regard, many studies have reported positive contributions by $\mathrm{THs}$ to $\mathrm{TB}$ management through collaboration with modern medicine in resource-poor settings [25, 33].

Knowledge, attitude and perceived stigma of the HCPs regarding TB were not significantly associated with age, sex or profession of the HCPs. The low scores might also be because the questionnaires were administered to all HCPs in spite of their engagement at the DOTS clinic during the study period.

\section{Limitations}

HCPs' knowledge, attitude and perceived stigma regarding $\mathrm{TB}$ and their perception about $\mathrm{THs}$ in kereyu pastoralist district were assessed. To the best of our knowledge, no similar study has been conducted in kereyu pastoralist communities in Ethiopia. This could 
Table 8 HCPs' perception of collaboration with THs for TB control in Keryu pastoralists District, Ethiopia

\begin{tabular}{|c|c|c|}
\hline Variables & Frequency $(n=108)$ & Percent $\%$ \\
\hline \multicolumn{3}{|l|}{ Traditional medicine exist } \\
\hline Yes & 12 & 11.1 \\
\hline People in this community go to TH for TB treatment & 48 & 44.4 \\
\hline \multicolumn{3}{|l|}{ Most preferred treatment option } \\
\hline Traditional medicine & 4 & 3.7 \\
\hline Modern medicine & 24 & 22.2 \\
\hline Reason for traditional medicine preference & 75 & 69.4 \\
\hline Easy accessibility & 26 & 24.1 \\
\hline Traditionally acceptable & 61 & 56.5 \\
\hline Less time taking & 14 & 13 \\
\hline Others & 7 & 6.5 \\
\hline \multicolumn{3}{|l|}{ Most Preferred to consult for health problems } \\
\hline THs & 37 & 34.3 \\
\hline Healthcare provider & 71 & 65.7 \\
\hline Know a patient who visited healthcare facility soon after visiting THs for TB & 30 & 27.8 \\
\hline Treated a person with TB referred by THs & 19 & 17.6 \\
\hline \multicolumn{3}{|l|}{ Why TH do not refer TB patients } \\
\hline TH can treat TB & 17 & 15.7 \\
\hline THs fear losing patient trust & 66 & 61.1 \\
\hline No collaboration mechanisms & 52 & 48.1 \\
\hline THs fear losing money & 40 & 37.0 \\
\hline No referral system & 26 & 24.1 \\
\hline No trust in modern medicine & 16 & 14.8 \\
\hline THs fear critics & 2 & 1.9 \\
\hline Do not know & 2 & 1.9 \\
\hline Others & 7 & 6.5 \\
\hline Accept THs practice & 19 & 17.6 \\
\hline \multicolumn{3}{|l|}{ Collaboration options } \\
\hline Cross visiting & 29 & 26.9 \\
\hline TH learning about TB & 16 & 14.8 \\
\hline Working together & 29 & 26.9 \\
\hline THs refer patients to healthcare facility & 29 & 26.9 \\
\hline Training THs & 2 & 1.9 \\
\hline Joint research programme & 3 & 2.8 \\
\hline
\end{tabular}

help to strengthen TB prevention and care activities in the district. However, this study has limitations because the report does not include TB case management/diagnosis and treatment practice of the HCPs at the TB unit. In addition, the self-reporting nature of the study and the fact that HCPs were allowed to return the completed questionnaire the next day might allow the respondents to receive external assistance in responding to the questions, affecting the results. Moreover, we were not able to include all HCPs reported to be working at the target healthcare facilities because of absence for training, workshops, leave of absence, transfer process, etc. Furthermore, the stigma questionnaire was not validated.

\section{Conclusions}

This study provides relevant information about the HCPs' knowledge gap regarding $\mathrm{TB}$, unfavourable attitude towards TB and TB prevention and care system. Our results showed that the HCPs had an unfavourable attitude towards the TB control system and had low 
perceived stigma towards TB patients. Training and workshops could help to fill in the knowledge gap of the HCPs' and change their attitude towards TB control system and TB patients. The HCPs interest in involving the community and THs in TB prevention and care activity is an opportunity to implement or strengthen the WHO's End TB strategy through community engagement.

\section{Additional file}

Additional file 1: Questionnaires (DOCX $40 \mathrm{~kb}$ )

\section{Acknowledgements}

The study was financially supported by the University of Oslo. We would like to thank Oromia regional health office for the permission to conduct the study and Fentalle district health office for facilitating the fieldwork. Last but not least, we would like to thank our respondents for their participation in the study.

\section{Funding}

This study was not funded by a grant. It is a PhD project and is supported by single student support programme at the University of Oslo.

\section{Availability of data and materials}

All data sets generated or analysed during the current study were included in this manuscript.

\section{Authors' contributions}

BTS developed the study, prepared the questionnaire, collected and analysed and interpreted the data and wrote the manuscript. FA developed the study and critically reviewed the manuscript. TB critically revised the manuscript.

All authors have read and approved the final manuscript.

\section{Ethics approval and consent to participate}

The Norwegian Social Science Data Service (NSD) and Ethical Review Committee of Jimma University, Jimma Ethiopia and Oromia Regional Health Office Ethical Review Committee, Addis Ababa, Ethiopia approved this study. The HCPs provided written consent to participate after receiving information about the study. We used codes instead of personal identifiers to maintain confidentiality and the anonymity of the interviewees.

\section{Consent for publication}

Not applicable.

\section{Competing interests}

The authors declare no competing interests.

\section{Publisher's Note}

Springer Nature remains neutral with regard to jurisdictional claims in published maps and institutional affiliations.

\section{Author details}

${ }^{1}$ Department of Health Education and Behavioral Science, Institute of Health, Jimma University, P.O. Box 378, Jimma, Ethiopia. ${ }^{2}$ Department of Population and Family Health, Institute of Health Science, Jimma University, P.O. Box 378, Jimma, Ethiopia. ${ }^{3}$ Department of Community Medicine and Global Health, Institute for Health and Society, Faculty of Medicine, University of Oslo, P.O. Box 1130, Blindern, 0318 Oslo, Norway.

Received: 28 February 2018 Accepted: 13 December 2018 Published online: 08 January 2019

\section{References}

1. WHO: Global tuberculosis report. World Health Organization: Global tuberculosis report 2017.

2. WHO. Ethiopia: on the road to ending. Tuberculosis. 2016.

3. Organization WH: WHO:Global tuberculosis report 2016. 2016.
4. Xu L, Gai R, Wang X, Liu Z, Cheng J, Zhou C, Liu J, Zhang H, Li H, Tang W. Socio-economic factors affecting the success of tuberculosis treatment in six counties of Shandong Province China. The International Journal of Tuberculosis and Lung Disease. 2010;14(4):440-6.

5. WHO: Stop TB partnership. The global plan to stop TB, 2006-2015. In: WHO/ HTM/STB/200635. Edn.; 2006.

6. WHO: World Health Organization;global tuberculosis control. WHO report Geneva 2011.

7. Naseer M, Khawaja A, Pethani AS, Aleem S. How well can physicians manage tuberculosis? A public-private sector comparison from Karachi Pakistan. BMC Health Serv Res. 2013;13(1):439.

8. Kanjee Z, Catterick K, Moll AP, Amico KR, Friedland GH. Tuberculosis infection control in rural South Africa: survey of knowledge, attitude and practice in hospital staff. J Hosp Infect. 2011;79(4):333-8.

9. Hashim DS, Al Kubaisy W, Al Dulayme A: Erratum: Knowledge, attitudes and practices survey among health care workers and tuberculosis patients in Iraq (Eastern Mediterranean Health Journal (2003) vol. 9 (4) (718-731)). East Mediterr Health J 2004, 10(4-5):493

10. Sima BT, Belachew T, Abebe F. Knowledge, attitude and perceived stigma towards tuberculosis among pastoralists; do they differ from sedentary communities? A comparative cross-sectional study. PLoS One. 2017;12(7): e0181032.

11. Legesse M, Ameni G, Mamo G, Medhin G, Shawel D, Bjune G, Abebe F. Knowledge and perception of pulmonary tuberculosis in pastoral communities in the middle and lower Awash Valley of Afar region, Ethiopia. BMC Public Health. 2010;10:187.

12. Tolossa D, Medhin G, Legesse M. Community knowledge, attitude, and practices towards tuberculosis in Shinile town, Somali regional state, eastern Ethiopia: a cross-sectional study. BMC Public Health. 2014;14(1):804.

13. Gele A, Sagbakken M, Abebe F, Bjune A. Barriers to tuberculosis care: a qualitative study among Somali pastoralists in Ethiopia. BMC research notes. 2010;3:86

14. Gele AA, Bjune G, Abebe F. Pastoralism and delay in diagnosis of TB in Ethiopia. BMC Public Health. 2009;9(1):5.

15. Zinsstag J, Ould Taleb M, Craig PS. Editorial: health of nomadic pastoralists: new approaches towards equity effectiveness. Tropical Med Int Health. 2006;11(5):565-8.

16. Belay M, Bjune G, Ameni G, Abebe F. Diagnostic and treatment delay among tuberculosis patients in Afar region, Ethiopia: a cross-sectional study. BMC Public Health. 2012:12:369.

17. Gebreegziabher SB, Bjune GA, Yimer SA. Patients' and health system's delays in the diagnosis and treatment of new pulmonary tuberculosis patients in west Gojjam zone, Northwest Ethiopia: a cross-sectional study. BMC Infect Dis. 2016;16(1):673.

18. Hussen A, Biadgilign S, Tessema F, Mohammed S, Deribe K, Deribew A. Treatment delay among pulmonary tuberculosis patients in pastoralist communities in bale zone Southeast Ethiopia. BMC Research Notes. 2012;5:320.

19. Teklehaimanot HD, Teklehaimanot A. Human resource development for a community-based health extension program: a case study from Ethiopia. Hum Resour Health. 2013;11(1):39.

20. Hashim D, Al Kubaisy W, Al Dulayme A. Knowledge, attitudes and practices survey among health care workers and tuberculosis patients in. Iraq. 2003.

21. WHO. Advocacy, communication and social mobilization for TB control: a guide to developing knowledge. In: Attitude and practice surveys; 2008.

22. Liew A. Understanding data, information, knowledge and their interrelationships. Journal of Knowledge Management Practice. 2007;8(2):1-16.

23. Sheik-Mohamed A, Velema JP. Where health care has no access: the nomadic populations of sub-Saharan Africa. Tropical Med Int Health. 1999; 4(10):695-707.

24. FMoH: Federal Democratic Republic of Ethiopia, Ministry of Health: health sector development Programme IV 2010/11-2014/15. 2010

25. Banerjee A, Sharma B, Ray A, Kannuri N, Venkateswarlu T. Acceptability of traditional healers as directly observed treatment providers in tuberculosis control in a tribal area of Andhra Pradesh India. Int J Tuberc Lung Dis. 2004; 8(10):1260-5.

26. Van Brakel WH. Measuring health-related stigma-a literature review. Psychology, Health and Medicine. 2006;11(3):307-34.

27. Efron R. What is perception? In: Proceedings of the Boston colloquium for the philosophy of science 1966/1968: 1969: Springer; 1969. p. 137-73.

28. Noé A, Ribeiro RM, Anselmo R, Maixenchs M, Sitole L, Munguambe K, Blanco S, le Souef P, García-Basteiro AL. Knowledge, attitudes and practices 
regarding tuberculosis care among health workers in southern Mozambique. BMC Pulmonary Medicine. 2017;17:2.

29. Buregyeya E, Kulane A, Colebunders R, Wajja A, Kiguli J, Mayanja H, Musoke P, Pariyo G, Mitchell E. Tuberculosis knowledge, attitudes and health-seeking behaviour in rural Uganda. Int J Tuberc Lung Dis. 2011;15.

30. Lertkanokkun S, Okanurak K, Kaewkungwal J, Meksawasdichai N. Healthcare providers' knowledge, attitudes \& practices regarding tuberculosis care. JItMM2012 PrOcEEDInGs. 2013;2:1-10.

31. Dodor E. Health professionals expose TB patients to stigmatization in society: insights from communities in an urban district in Ghana. Ghana Medical Journal. 2008;42(4):144

32. Wu P-S, Chou P, Chang N-T, Sun W-J, Kuo H-S. Assessment of changes in knowledge and stigmatization following tuberculosis training workshops in Taiwan. J Formos Med Assoc. 2009;108(5):377-85.

33. Viney K, Johnson P, Tagaro M, Fanai S, Linh N, Kelly P, Harley D, Sleigh A. Traditional healers and the potential for collaboration with the national tuberculosis programme in Vanuatu: results from a mixed methods study. BMC Public Health. 2014;14(1):393.

Ready to submit your research? Choose BMC and benefit from:

- fast, convenient online submission

- thorough peer review by experienced researchers in your field

- rapid publication on acceptance

- support for research data, including large and complex data types

- gold Open Access which fosters wider collaboration and increased citations

- maximum visibility for your research: over $100 \mathrm{M}$ website views per year

At $\mathrm{BMC}$, research is always in progress.

Learn more biomedcentral.com/submissions 